\title{
In Vivo Evaluation of TNF-Alpha in the Lungs of Patients Affected by Sarcoidosis
}

\author{
Filippo Galli, ${ }^{1}$ Tiziana Lanzolla, ${ }^{1}$ Vittorio Pietrangeli, ${ }^{2}$ Gaurav Malviya, ${ }^{1}$ \\ Alberto Ricci, ${ }^{2}$ Pierdonato Bruno, ${ }^{2}$ Paola Ragni, ${ }^{1}$ Francesco Scopinaro, ${ }^{1}$ \\ Salvatore Mariotta, ${ }^{2}$ and Alberto Signore ${ }^{1}$
}

${ }^{1}$ Nuclear Medicine Unit, Department of Medical-Surgical Sciences and Translational Medicine, Faculty of Medicine and Psychology, Ospedale S. Andrea, "Sapienza" University of Rome, Via di Grottarossa 1035, 00189 Roma, Italy

${ }^{2}$ Pneumology Unit, Department of Clinical and Molecular Medicine, Faculty of Medicine and Psychology, Ospedale S. Andrea, "Sapienza" University of Rome, Via di Grottarossa 1035, 00189 Roma, Italy

Correspondence should be addressed to Alberto Signore; alberto.signore@uniromal.it

Received 7 June 2014; Revised 9 August 2014; Accepted 11 August 2014

Academic Editor: Andor Glaudemans

Copyright (C) 2015 Filippo Galli et al. This is an open access article distributed under the Creative Commons Attribution License, which permits unrestricted use, distribution, and reproduction in any medium, provided the original work is properly cited.

\begin{abstract}
Introduction. Sarcoidosis is a multisystemic granulomatous disorder characterized by multiple noncaseating granulomas involving intrathoracic lymph nodes and lung parenchyma. Recently, the use of anti-tumor necrosis factor alpha (anti-TNF $\alpha$ ) agents has been introduced for therapy of chronic and refractory sarcoidosis with controversial results. Infliximab (Remicade) is a chimeric monoclonal antibody $(\mathrm{mAb})$ that recognizes and binds $\mathrm{TNF} \alpha$, neutralizing its biological effects. In the present study, ${ }^{99 \mathrm{~m}} \mathrm{Tc}$ labelled infliximab was used to study the expression of TNF $\alpha$ in sarcoid lesions and to evaluate its role as a predictive marker in response to therapy with Remicade. Material and Methods. A total of 10 patients with newly diagnosed sarcoidosis were enrolled together with 10 control patients affected by rheumatoid arthritis. All patients were studied by planar imaging of the chest with ${ }^{99 \mathrm{~m}} \mathrm{Tc}$-infliximab at $6 \mathrm{~h}$ and $24 \mathrm{~h}$ and total body $\left[{ }^{18} \mathrm{~F}\right]-$ FDG PET/CT. Regions of interest were drawn over the lungs and the right arm and targetto-background ratios were analysed for ${ }^{99} \mathrm{~m}$ Tc-infliximab. SUV ${ }_{\text {mean }}$ and $\mathrm{SUV}_{\max }$ were calculated over lungs for FDG. Results and Discussion. Image analysis showed low correlation between $T / B$ ratios and BAL results in patients despite positivity at $\left[{ }^{18} \mathrm{~F}\right]-\mathrm{FDG}$ PET. Conclusion. In conclusion, patients with newly diagnosed pulmonary sarcoidosis, with FDG-PET and BAL positivity, showed a negative ${ }^{99 \mathrm{~m}} \mathrm{Tc}$-infliximab scintigraphy.
\end{abstract}

\section{Introduction}

Sarcoidosis is a multisystemic granulomatous disorder characterized by multiple noncaseating granulomas involving intrathoracic lymph nodes and lung parenchyma. Inflammatory lesions can occur also in other organs like eyes and skin and, although less frequently, also in liver, spleen, extrathoracic lymph nodes, salivary glands, heart, nervous system, bones, and muscles. Even if its aetiology is still unknown, the role of cell-mediated immunity in the formation and in the maintenance of typical granulomas has been clarified [ 1 , 2]. For this reason immunosuppressive therapy remains the gold standard for treatment and in particular corticosteroid are used as a first line therapy [3]. However, serious side effects of steroid therapy and the loss of long-term efficacy of this treatment have led researchers to use new drugs. Recently, the use of anti-tumor necrosis factor alpha (anti$\mathrm{TNF} \alpha$ ) agents has been introduced for therapy of chronic and refractory sarcoidosis [4-6]. TNF $\alpha$ is an important cytokine released by alveolar activated macrophages, implicated in the development of granulomas. Infliximab (Remicade) is a chimeric monoclonal antibody $(\mathrm{mAb})$ that recognizes and binds TNF $\alpha$, neutralizing its biological effects [7]. However, the effectiveness of such therapy is still uncertain and under investigation [8]. It is indeed not well known if $\mathrm{TNF} \alpha$ is sufficiently present in sarcoid lesions to play a relevant biological role despite the fact that its presence in BAL has been shown to correlate with the severity of alveolitis [9]. 
Nevertheless, which patient and which lesion have high levels of TNF $\alpha$ and may respond to anti-TNF $\alpha$ therapy is difficult to ascertain. In this view, the assessment of TNF $\alpha$ in sarcoid lesions by a noninvasive technique could be important to strengthen the hypothesis behind the use of anti-TNF $\alpha$ drugs and to select patients that could respond to therapy. Currently there are no specific diagnostic tools to directly evaluate the presence of anti-TNF $\alpha$ in sarcoid lesions but several methods have been reported for measuring disease activity. Chest Xray and pulmonary function tests (spirometry), the measurement of serum angiotensin-converting-enzyme (ACE) levels and ${ }^{67} \mathrm{Ga}$-citrate scintigraphy, and bronchoalveolar lavage (BAL) with evaluation of $\mathrm{CD}^{+}$and $\mathrm{CD}^{+}$lymphocytes have all been and still are used as surrogate markers of diseases activity $[10,11]$. In particular, $\left[{ }^{18} \mathrm{~F}\right]$-Fluoro-2-deoxyD-glucose PET/CT ( $\left[{ }^{18} \mathrm{~F}\right]$-FDG PET/CT) has been shown to be of high clinical value for evaluation of disease activity and extent and for therapy follow-up [12-15].

In the present study, we have used ${ }^{99 \mathrm{~m}}$ Technetium $\left({ }^{99 \mathrm{~m}} \mathrm{Tc}\right)$ labelled infliximab in patients with newly diagnosed sarcoidosis for noninvasive in vivo scintigraphic evaluation of the presence of TNF $\alpha$ in pulmonary and lymph nodal sarcoid lesions. Patients were also studied by $\left[{ }^{18} \mathrm{~F}\right]-\mathrm{FDG}$ PET/CT and BAL with lymphocyte phenotyping for complete evaluation of disease activity.

\section{Patients and Methods}

2.1. Patients and Diagnosis. Study design included 20 patients with newly diagnosed sarcoidosis at stages II-III to be prospectively recruited for $\left[{ }^{18} \mathrm{~F}\right]$-FDG-PET/CT and ${ }^{99 \mathrm{~m}} \mathrm{Tc}$ infliximab scintigraphy and 10 control subjects (patients without sarcoidosis but affected by rheumatoid arthritis (RA) to evaluate disease activity in joints). After enrolling all controls ( 7 females and 3 males, mean age $54 \pm 10$ years) and 10 sarcoidosis patients ( 8 females and 2 males, mean age $55 \pm 8$ years) we performed an interim analysis and decided to stop recruitment, based on results. Sarcoidosis patients were symptomatic and presented respiratory symptoms of the disease, without involvement of specific organs but lungs, thoracic and extrathoracic lymph nodes. They were also subjected to a standard assessment that included history and physical examination, with particular attention to respiratory disorders, blood test with peripheral blood counts and lymphocytes count ratio, and X-ray examination of the chest, including X-ray and high-resolution CT, bronchoscopy with bronchoalveolar lavage and bronchial biopsy, and analysis of BAL with lymphocytes immune-phenotyping ( 2 patients refused to perform the BAL). The diagnosis of sarcoidosis was performed using histological demonstration of the presence of the typical noncaseating granulomas; other diseases such as Wegener's granulomatosis, tuberculosis, aspergillosis, and neoplastic diseases were excluded for each patient. None of enrolled patients had previously been treated with corticosteroid therapy or immunosuppressive drugs. The study was approved by the local medical ethical committee and each patient expressed written informed consensus.
2.2. $\left[{ }^{18} F\right]-F D G$ PET/CT. Within 2 months from clinical diagnosis of sarcoidosis, a $\left[{ }^{18} \mathrm{~F}\right]-$ FDG PET/CT was performed after fasting for at least $6 \mathrm{~h}$ before the intravenous injection of $\left[{ }^{18} \mathrm{~F}\right]-\mathrm{FDG}$ and with a serum glucose level lower than $160 \mathrm{mg} / \mathrm{dL}$. Diazepam (5 mg) was administered to reduce muscle activity and activation of the brown fat. The activity of $\left[{ }^{18} \mathrm{~F}\right]-\mathrm{FDG}$ to be administered was calculated for each patient according to the following formula [(weight in $\mathrm{Kg} / 10 \times 37 \mathrm{MBq})+1]$. The PET scan was performed with hybrid PET/CT Gemini (Philips, NL). Imaging acquisition started 60 minutes after the radiopharmaceutical injection from the upper thigh to the head, with a preliminary lowdose unenhanced CT scan (16 slice, $100 \mathrm{mAs}$ ) followed by PET imaging (2.5 min per bed position, 3D mode, matrix). Images were reconstructed with $\mathrm{CT}$ data by common iterative algorithm (OSEM, ordered subset expectation maximization, 2 iterations, 28 subsets) to obtain attenuation corrected images and anatomical mapping on functional images. $\left[{ }^{18} \mathrm{~F}\right]$ FDG PET/CT images were visually analysed and disease activity was assessed separately in the mediastinum, hilum, lung parenchyma, extrapulmonary lymph nodes, even with obvious evaluation of liver, spleen, bone marrow, bones, and joints, in order to highlight a possible involvement of these organs. Each site was scored either positive or negative (positive $=\left[{ }^{18} \mathrm{~F}\right]$-FDG uptake higher than background; negative $=\left[{ }^{18} \mathrm{~F}\right]$-FDG uptake lower or equal to background). The semiquantitative analysis was based on the analysis of standardized uptake value (SUV) evaluated as $\mathrm{SUV}_{\max }$ and $\mathrm{SUV}_{\text {mean }}$, obtained by drawing regions of interest (ROIs) on transaxial sections of lung parenchyma at the level of the $3 \mathrm{rd}, 5$ th, and 7 th thoracic vertebral body. The SUV values obtained were then compared with those obtained in the control population.

2.3. ${ }^{99 m}$ Tc-Infliximab Scintigraphy. The mAb infliximab was radiolabelled as previously described [16]. Briefly, $200 \mu \mathrm{L}$ of ${ }^{99} \mathrm{mcO}_{4}{ }^{-}(666 \mathrm{MBq})$ was added to $200 \mu \mathrm{L}$ of reduced $\mathrm{mAb}$ ( $200 \mathrm{mg} / \mathrm{mL}$ ) followed by $7 \mu \mathrm{L}$ of methylene diphosphonate (MDP). After 10 minutes of incubation at room temperature, quality controls were performed by instant thin layer chromatography (ITLC). Silica gel strips and $0.9 \% \mathrm{NaCl}$ solution were used, respectively, as stationary and mobile phase for labelling efficiency determination. Albumin precoated silica gel strips and $\mathrm{H}_{2} \mathrm{O}:$ EtOH $: \mathrm{NH}_{3}(5: 3: 1)$ solution were used for colloids evaluation.

Within 1 week from the PET/CT scan, all patients performed a scintigraphic study with radiolabelled anti-TNF $\alpha$ after intravenous injection of $370 \mathrm{MBq}$ of ${ }^{99 \mathrm{~m}} \mathrm{Tc}$-infliximab. Whole body images and planar static images of chest were acquired at $6 \mathrm{~h}$ and $24 \mathrm{~h}$ after injection with a large field of view, two head, gamma camera (Sky Light, Philips, NL) equipped with low-energy high-resolution collimators and $20 \%$ energy windows centred at $140 \mathrm{KeV}$. Whole body images (matrix $512 \times 1024)$ were acquired at a speed of $10 \mathrm{~cm} / \mathrm{min}$ at $6 \mathrm{~h}$ and $5 \mathrm{~cm} / \mathrm{min}$ at $24 \mathrm{~h}$ taking into account the decay of the radionuclide. Anterior and posterior thorax images (matrix $256 \times 256)$ were acquired for 300 seconds at $6 \mathrm{~h}$ and 600 seconds at $24 \mathrm{~h}$. 


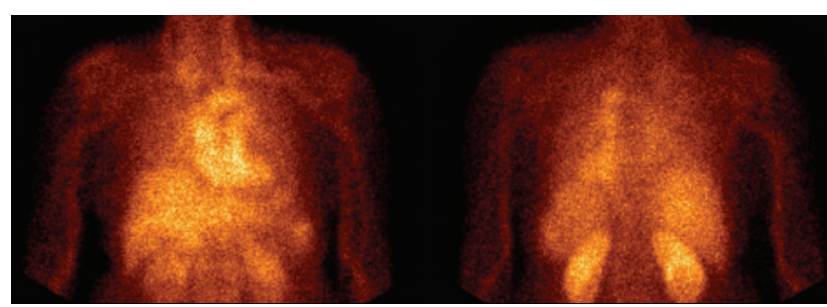

(a)
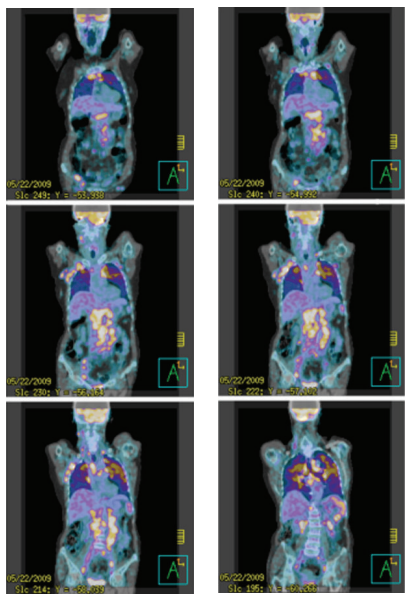

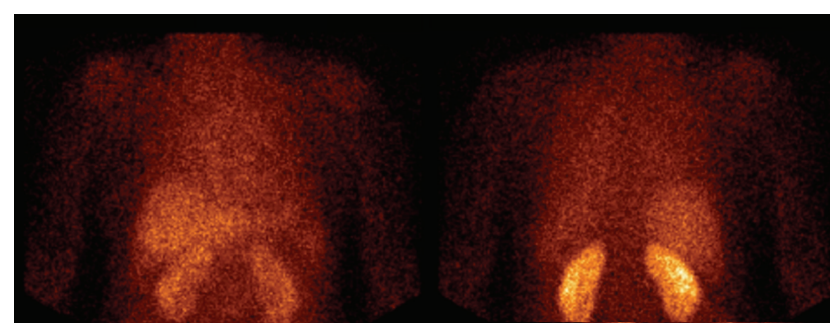

(b)
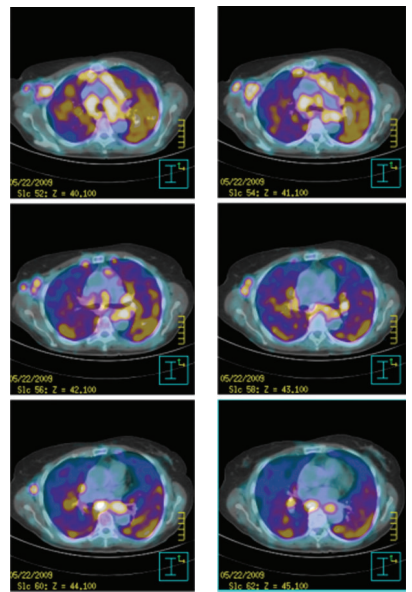

(c)

Figure 1: ${ }^{99 \mathrm{~m}}$ Tc-Infliximab scintigraphy of a sarcoidosis patient (patient 3/F) acquired at $6 \mathrm{~h}$ (anterior and posterior views (a)) and at $24 \mathrm{~h}$ (anterior and posterior views (b)) showing a moderate and diffuse uptake in the lung parenchyma. $\left[{ }^{18} \mathrm{~F}\right]$-FDG PET/CT images of the same patient showing a focal/hyleal uptake (coronal and transaxial sections (c)).

The results of scintigraphic studies were qualitatively analysed to identify any labelled mAb uptake and were visually compared with the pathological findings on PET images. A semiquantitative analysis was performed drawing ROIs over each lung parenchyma $\left(\mathrm{ROI}_{\text {lung }}\right)$ including hilum, but excluding heart and spine, and a ROI over the upper right arm $\left(\mathrm{ROI}_{\text {arm }}\right)$ as background, excluding joints. The counts were normalized by area and the target-to-background $(T / B)$ ratio $\left(\mathrm{ROI}_{\text {lung }} / \mathrm{ROI}_{\text {arm }}\right)$ was calculated at $6 \mathrm{~h}$ and $24 \mathrm{~h}$ for each lung in anterior and in posterior views. The average value of anterior and posterior values was considered for each patient. Results were compared with control subjects that underwent ${ }^{99 \mathrm{~m}} \mathrm{Tc}$-infliximab for RA and therefore considered "pulmonary negative."

2.4. Statistical Analysis. For each patient the average values of $\mathrm{SUV}_{\max }$ and $\mathrm{SUV}_{\text {mean }}$, obtained in lung parenchyma, were calculated in both sarcoidosis patients and controls, obtaining for each group the mean value \pm SD. Similarly, the mean values $\pm \mathrm{SD}$ of $T / B$ ratios in sarcoidosis patients and control group were calculated at each time point $(6 \mathrm{~h}$ and $24 \mathrm{~h}$ ). In sarcoidosis population correlations were made between mean SUV values and mean $T / B$ ratio, mean SUV values and lymphocytes immune-phenotyping on BAL, and mean $T / B$ ratio and lymphocytes immune-phenotyping on BAL, in order to assess the diagnostic accuracy of each methodology to evaluate disease activity. Student's $t$-test was applied to assess the significance of relationship between the $T / B$ ratio of sarcoidosis group and $T / B$ ratio of control subjects.

\section{Results}

3.1. $\left[{ }^{18} F\right]-F D G$ PET/TC. The qualitative analysis performed on PET/CT studies in lungs showed complete agreement with the staging previously made by pulmonologists according to radiological and biochemical findings (Figure 1). Furthermore, in 3/10 patients PET showed other extrapulmonary sites of disease, with involvement of axillary and abdominalpelvic lymph nodes, not previously known, demonstrating its high sensitivity. The mean values $\pm S D$ of $S U V_{\max }$ obtained in patients with sarcoidosis were $4.43 \pm 3.20$ whereas in control subjects mean values $\pm \mathrm{SD}$ of SUV $\mathrm{max}_{\max }$ were $1.18 \pm 0.20(P<$ $0.001)$. These data are an expression of inflammation involvement of lung parenchyma in patients with sarcoidosis. The values of $S U V_{\text {max }}$ and $S U V_{\text {mean }}$ correlated perfectly; therefore for subsequent analysis only $\mathrm{SUV}_{\max }$ will be reported even if also $\mathrm{SUV}_{\text {mean }}$ has always been considered. Despite the higher values of $S U V_{\max }$ in patients with sarcoidosis with respect to controls, it was not possible to find a cut-off value that could allow the correlation of the extent of uptake in the lung parenchyma with the degree of alveolitis. It was not also possible to obtain a significant correlation between lymphocyte immune-phenotyping results of BAL (with particular reference to $\mathrm{CD} 4^{+} / \mathrm{CD}^{+}$ratio) and the 
TABLE 1: Summary of SUV obtained by $\left[{ }^{18} \mathrm{~F}\right]$-FDG PET/CT and T/B values (average of right and left lung calculated in anterior and posterior images) in patients with sarcoidosis.

\begin{tabular}{|c|c|c|c|c|c|}
\hline Number/Sex & Stage & $\mathrm{SUV}_{\max }$ & $\mathrm{SUV}_{\text {mean }}$ & $T / B 6 \mathrm{~h}$ & $T / B 24 \mathrm{~h}$ \\
\hline $1 / \mathrm{F}$ & I & 1.91 & 0.54 & 4.16 & 2.84 \\
\hline $2 / \mathrm{F}$ & II & 3.47 & 0.99 & 4.34 & 2.75 \\
\hline $3 / \mathrm{F}$ & II & 4.38 & 2.19 & 3.52 & 3.49 \\
\hline $4 / \mathrm{F}$ & II & 2.64 & 0.79 & 4.82 & 3.97 \\
\hline $5 / \mathrm{M}$ & I-II & 3.05 & 1.02 & 3.61 & 3.14 \\
\hline $6 / F$ & II & 5.28 & 1.25 & 4.77 & 3.24 \\
\hline $7 / \mathrm{M}$ & I & 2.23 & 0.73 & 4.14 & 2.72 \\
\hline $8 / \mathrm{F}$ & II & 12.87 & 4.55 & 4.73 & 3.41 \\
\hline $9 / \mathrm{F}$ & II & 3.01 & 0.88 & 3.43 & 2.49 \\
\hline $10 / \mathrm{F}$ & II & 5.48 & 0.90 & 4.73 & 3.42 \\
\hline \multicolumn{2}{|c|}{ Mean \pm SD } & $4.43 \pm 3.2$ & $1.38 \pm 1.2$ & $4.22 \pm 0.55$ & $3.15 \pm 0.45$ \\
\hline
\end{tabular}

$\mathrm{SUV}_{\max }$ values of patients with sarcoidosis. No correlation was also observed between $\mathrm{SUV}_{\text {max }}$ or $\mathrm{SUV}_{\text {mean }}$ values and the $\mathrm{CD} 4^{+} / \mathrm{CD}^{+}$ratio in blood.

3.2. ${ }^{99 m}$ Tc-Infliximab Scintigraphy. The qualitative analysis of scintigraphy with ${ }^{99 \mathrm{~m}}$ Tc-infliximab showed no pathological focal accumulation of the labeled antibody (Table 1). Both images at $6 \mathrm{~h}$, characterized by high vascular activity, and images at $24 \mathrm{~h}$ did not show the same pathological uptakes highlighted in the preliminary PET study (Figures 1 and 2). The pulmonary distribution of the two radiopharmaceuticals was different, being predominantly diffused in the case of ${ }^{99 \mathrm{~m}} \mathrm{Tc}$-infliximab and rather focal with ileal involvement in the PET scans.

Comparing $T / B$ ratios on ${ }^{99 \mathrm{~m}} \mathrm{Tc}$-infliximab scintigraphy at $6 \mathrm{~h}$ and $24 \mathrm{~h}$, with $\mathrm{SUV}_{\max }$ values of pulmonary uptake of FDG, no significant correlation was observed between these parameters. In only three patients a detectable diffuse bilateral lung uptake of anti-TNF $\alpha$ at $6 \mathrm{~h}$ and $24 \mathrm{~h}$ on scintigraphic images was present, which could indicate increased levels of TNF $\alpha$ in lung parenchyma of these patients. When we compared the mean values of lung uptake of labelled anti-TNF $\alpha \mathrm{mAb}$ in sarcoidosis patients and control subjects, we found significant differences at $6 \mathrm{~h}(4.28 \pm 0.57$ versus $3.2 \pm 0.74$; patients versus controls; $P=0.002)$ but not at $24 \mathrm{~h}(3.15 \pm 0.45$ versus $2.7 \pm 0.65$; patients versus controls; $P=0.057)$. A moderate correlation was found between $\mathrm{CD}^{+} / \mathrm{CD}^{+}$ratio peripheral blood lymphocytes and the value of $T / B$ ratio at $6 \mathrm{~h}$ (Figure 3 ) but no correlation was found between average value of $T / B$ ratio at $6 \mathrm{~h}$ or $24 \mathrm{~h}$ and, respectively, $\mathrm{CD} 4^{+} / \mathrm{CD}^{+}$ratio and cellularity of BAL (Figure 4).

\section{Discussion}

In the last decade, systemic autoimmune disease therapy has been revolutionized by the availability of biological drugs or monoclonal antibodies, directed against a specific target implicated in the pathogenesis of disease. In patients with active sarcoidosis, the release of TNF $\alpha$ by activated alveolar macrophages has been widely documented in a lot of previous studies [17-21]. Infliximab (Remicade) is a chimeric monoclonal antibody of the type $\operatorname{IgG} 1 \kappa$, with a variable region derived from murine antihuman TNF $\alpha$ and a constant sequence of human-derived IgG1. It was one of the first biological drugs to be used for the treatment of patients with sarcoidosis refractory to conventional therapy [5, 6, 22-24]. In particular, the multicenter phase II study of Baughman et al. [25] showed that in patients with sarcoidosis, symptomatic, refractory to corticosteroid therapy, treated with infliximab, there was a significant improvement of the forced vital capacity (FVC) without significant side effects related to the use of the drug. However, Panselinas et al. [26] showed, in a retrospective study, that in the majority of patients treated with infliximab, there was a recurrence of the disease about 3 months after discontinuation of the drug. Since biological therapies, such as infliximab, are extremely expensive, it would be desirable to be able to accurately select patients who really might benefit from this type of therapies. To date, however, there are no diagnostic markers for therapy decision making. In order to answer this question, we undertook a study to assess whether scintigraphy with ${ }^{99 \mathrm{~m}} \mathrm{Tc}$-infliximab, showing directly the presence of TNF $\alpha$ in the lesions, may represent a marker for predicting the efficacy of biological therapy with anti-TNF $\alpha$ and then select the patients suitable for this type of treatment $[27,28]$. Infliximab was labelled with high labelling efficiency, high specific activity, and stability. Preliminary studies in vitro in animals and humans have shown its usefulness in the evaluation of patients with Crohn's disease and rheumatoid arthritis [2931]. $\left[{ }^{18} \mathrm{~F}\right]-$ FDG PET has proven to be a very sensitive method in the evaluation of disease activity. Many studies have shown its higher sensitivity compared to ${ }^{67}$ Gallium-citrate scintigraphy in the evaluation of disease and follow-up of therapy $[14,32-38]$. However, $\left[{ }^{18} \mathrm{~F}\right]-$ FDG PET lacks specificity and cannot be used for the selection of patients to be treated with anti-TNF $\alpha$. Its main role remains the diagnostic confirmation of disease, evaluation of the extension of the sites of disease, and the follow-up. It is therefore right to compare the role 


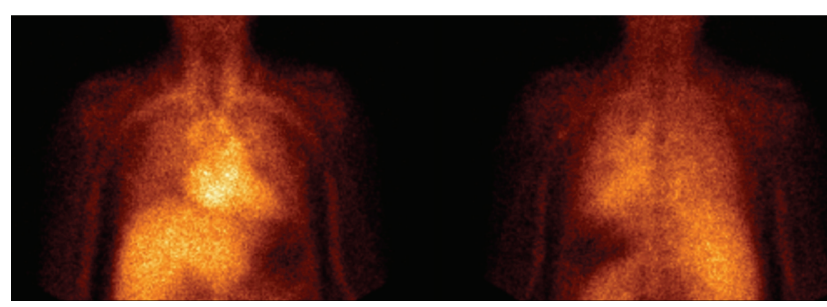

(a)

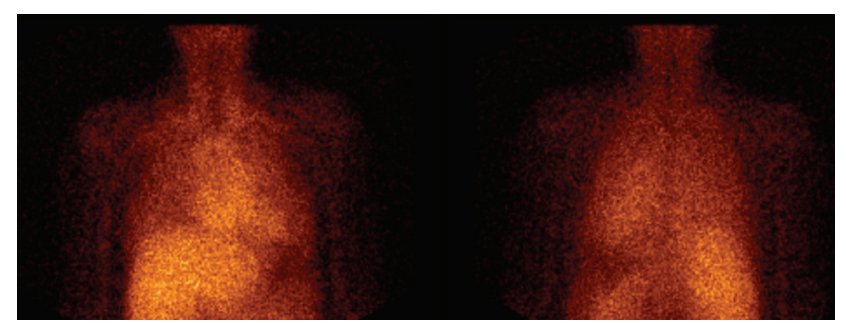

(b)
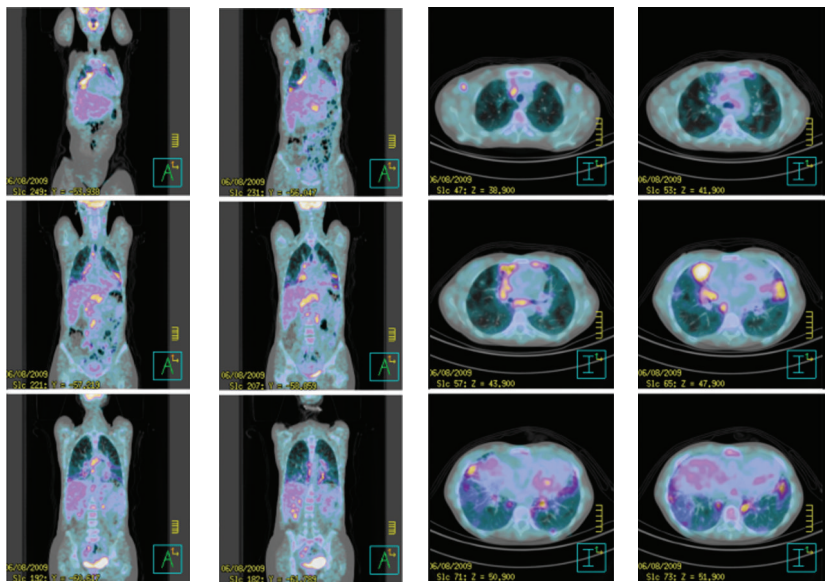

(c)

Figure 2: ${ }^{99 \mathrm{~m}} \mathrm{Tc}$-Infliximab scintigraphy of a sarcoidosis patient (patient $4 / \mathrm{F}$ ) acquired at $6 \mathrm{~h}$ (anterior and posterior views (a)) and at $24 \mathrm{~h}$ (anterior and posterior views (b)) showing a moderate and diffuse uptake in the lung parenchima. $\left[{ }^{18} \mathrm{~F}\right]$-FDG PET/CT images of the same patient showing a focal/hyleal uptake (coronal and transaxial sections (c)).

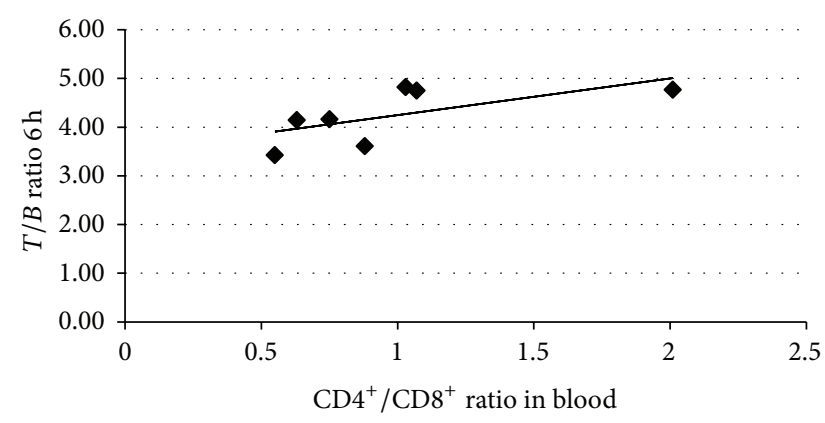

FIgURE 3: Correlation between lung uptake of ${ }^{99 \mathrm{~m}} \mathrm{Tc}$-infliximab at $6 \mathrm{~h}(T / B$ ratio $)$ and $\mathrm{CD}^{+} / \mathrm{CD}^{+}$ratio in peripheral blood lymphocytes. Correlation coefficient is $r=0.2357$ and $P=0.05$.

of scintigraphy with ${ }^{99 \mathrm{~m}} \mathrm{Tc}$-infliximab in the evaluation of disease with the findings obtained with $\left[{ }^{18} \mathrm{~F}\right]-$ FDG PET, but mainly for the selection of patients suitable for treatment with unlabelled anti-TNF $\alpha$ mAb. From our data, although on a limited series, it appears that with a qualitative examination, PET confirmed the staging performed by pulmonologists and allowed us to identify locations of extrathoracic disease, like axillaries and abdominopelvic lymph nodes. Inflammatory events in the lung parenchyma of sarcoidosis patients have been confirmed by higher SUV $\mathrm{max}_{\text {ax }}$ and SUV $\mathrm{mean}_{\text {mith respect }}$ to normal subjects. The lack of correlation between the

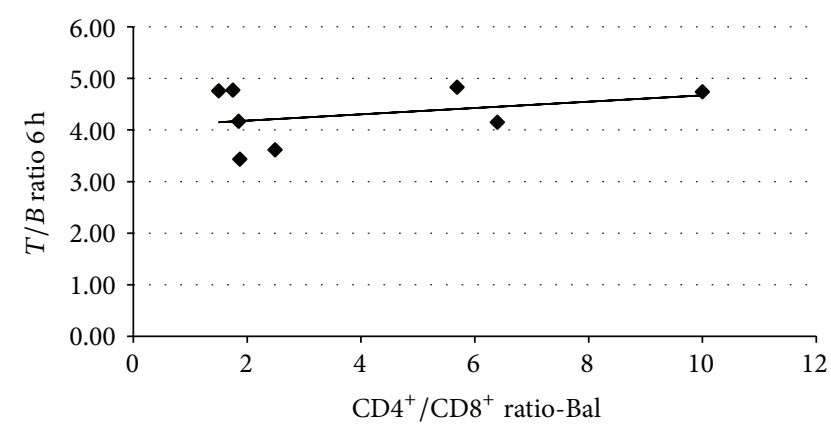

FIgURE 4: Correlation between lung uptake of ${ }^{99 \mathrm{~m}}$ Tc-infliximab at $6 \mathrm{~h}(T / B$ ratio $)$ and $\mathrm{CD} 4^{+} / \mathrm{CD}^{+}$ratio in lymphocytes from BAL. Correlation coefficient is $r=0.6487$ and $P=$ n.s.

$\mathrm{CD} 4^{+} / \mathrm{CD}^{+}$lymphocytes ratio in BAL and the values of both $\mathrm{SUV}_{\text {max }}$ and $\mathrm{SUV}_{\text {mean }}$ in the lung could be explained by the fact that the $\left[{ }^{18} \mathrm{~F}\right]-\mathrm{FDG}$ is taken up by various cell types involved in the inflammatory sarcoid granuloma, confirming its poor specificity. Alternatively BAL is performed in a single lung segment whereas SUV was calculated over the whole lungs. Scintigraphy with labelled anti-TNF $\alpha \mathrm{mAb}$ was qualitatively positive in 4 out of 10 patients, showing at $6 \mathrm{~h}$ and $24 \mathrm{~h}$ a widespread uptake of the radiopharmaceutical in both lungs. The values of $T / B$ ratio calculated, on both the $6 \mathrm{~h}$ 
and $24 \mathrm{~h}$ images, did not correlate with the values of $\mathrm{SUV}_{\max }$ and $\mathrm{SUV}_{\text {mean }}$ calculated on $\mathrm{ROI}_{\text {lung }}$ of PET.

There are many possible explanations for this different pattern of ${ }^{18}$ F-FDG and ${ }^{99 m}$ Tc-infliximab in sarcoidosis patients. One of them is that the two radiopharmaceuticals show different aspects of the same phenomenon: the intense $\left[{ }^{18} \mathrm{~F}\right]-\mathrm{FDG}$ uptake by the cell populations responsible of alveolitis (macrophages, lymphocytes, etc.) and the presence of TNF $\alpha$ revealed by radiolabelled ${ }^{99 \mathrm{~m}}$ Tc-infliximab. Alternatively, there may be individual variability in the production of TNF $\alpha$ due to genetic reasons that depend on the stage of the disease. The lack of a clear focal uptake in some patients could also be caused by the long half-life of the anti-TNF $\alpha$ mAb that resulted in high background activity from the blood. This phenomenon is critical in highly perfused organs such as the lungs. In this case, the use of isotopes with longer half-life $\left({ }^{89} \mathrm{Zr}\right.$ or $\left.{ }^{111} \mathrm{In}\right)$ could help allowing to acquire images at later time points (e.g., $48 \mathrm{~h}$ or $72 \mathrm{~h}$ ) thus improving $T / B$ ratio due to clearance of radiopharmaceutical from the blood. Moreover, it should be kept in mind that, contrarily to what happens in lesions where the targets of a radiopharmaceutical are membrane bound receptors, TNF $\alpha$ is also a soluble molecule and a possible washout or low concentration in the lesions could prevent the visualization of distinctive foci. Indeed, on the basis of the review of literature, the most responsive patients to therapy with infliximab appear to be those with extrapulmonary disease, with involvement of skin, nervous system, bone, and ocular disease; it would be interesting to study these patients with ${ }^{99 \mathrm{~m}} \mathrm{Tc}$-infliximab scintigraphy in order to effectively assess the presence of $\mathrm{TNF} \alpha$ in other extrapulmonary tissues affected by sarcoidosis.

Our choice was to investigate patients with newly diagnosed sarcoidosis that did not undergo prior therapies, based on the need to study "naive" patients in which no previous immunosuppressive therapy was administered. Despite what we expected the $T / B$ ratio calculated at $6 \mathrm{~h}$ and $24 \mathrm{~h}$ did not correlate with the amount of lymphocytes in BAL, indicating that not all immune-mediated phenomena are characterized by high production of TNF $\alpha$.

\section{Conclusions}

Labelled anti-TNF $\alpha$ mAb scintigraphy could be a good tool for the selection of patients to be treated with antiTNF $\alpha$ drugs; however, in our study most of the examined patients showed a negative ${ }^{99 \mathrm{~m}} \mathrm{Tc}$-infliximab scintigraphy, underlining a low presence of $\mathrm{TNF} \alpha$ even if $\left[{ }^{18} \mathrm{~F}\right]-\mathrm{FDG}$ $\mathrm{PET} / \mathrm{CT}$ was highly positive.

\section{Conflict of Interests}

The authors declare that there is no conflict of interests regarding the publication of this paper.

\section{Authors' Contribution}

Filippo Galli and Tiziana Lanzolla equally contributed to this paper.

\section{References}

[1] R. P. Baughman, E. E. Lower, and R. M. Du Bois, "Sarcoidosis," The Lancet, vol. 361, no. 9363, pp. 1111-1118, 2003.

[2] M. A. Judson, "Sarcoidosis: clinical presentation, diagnosis, and approach to treatment," The American Journal of the Medical Sciences, vol. 335, no. 1, pp. 26-33, 2008.

[3] A. P. Croft, D. Situnayake, O. Khair et al., "Refractory multisystem sarcoidosis responding to infliximab therapy," Clinical Rheumatology, vol. 31, no. 6, pp. 1013-1018, 2012.

[4] J. P. Utz, A. H. Limper, S. Kalra et al., "Etanercept for the treatment of stage II and III progressive pulmonary sarcoidosis," Chest, vol. 124, no. 1, pp. 177-185, 2003.

[5] J. D. Doty, J. E. Mazur, and M. A. Judson, "Treatment of sarcoidosis with infliximab," Chest, vol.127, no. 3, pp. 1064-1071, 2005.

[6] S. Saleh, S. Ghodsian, V. Yakimova, J. Henderson, and O. P. Sharma, "Effectiveness of infliximab in treating selected patients with sarcoidosis," Respiratory Medicine, vol. 100, no. 11, pp. 2053-2059, 2006.

[7] D. Sánchez-Cano, J. L. Callejas-Rubio, R. Ruiz-Villaverde, R. Ríos-Fernández, and N. Ortego-Centeno, "Off-label uses of anti-TNF therapy in three frequent disorders: behçet's disease, sarcoidosis , and noninfectious uveitis," Mediators of Inflammation, vol. 2013, Article ID 286857, 10 pages, 2013.

[8] P. Korsten, M. Mirsaeidi, and N. J. Sweiss, "Nonsteroidal therapy of sarcoidosis," Current Opinion in Pulmonary Medicine, vol. 19, no. 5, pp. 516-523, 2013.

[9] J. Domagała-Kulawik, T. Skirecki, M. Maskey-Warzechowska, H. Grubek-Jaworska, and R. Chazan, "Bronchoalveolar lavage total cell count in interstitial lung diseases-does it matter?" Inflammation, vol. 35, no. 3, pp. 803-809, 2012.

[10] R. P. Baughman, Y. Ploysongsang, R. D. Roberts, and L. Srivastava, "Effects of sarcoid and steroids on angiotensinconverting enzyme," American Review of Respiratory Disease, vol. 128, no. 4, pp. 631-633, 1983.

[11] R. H. Winterbauer, J. Lammert, M. Selland, R. Wu, D. Corley, and S. C. Springmeyer, "Bronchoalveolar lavage cell populations in the diagnosis of sarcoidosis," Chest, vol. 104, no. 2, pp. 352361, 1993.

[12] Y. Nishiyama, Y. Yamamoto, K. Fukunaga et al., "Comparative evaluation of 18F-FDG PET and 67Ga scintigraphy in patients with sarcoidosis," Journal of Nuclear Medicine, vol. 47, no. 10, pp. 1571-1576, 2006.

[13] J. J. Braun, R. Kessler, A. Constantinesco, and A. Imperiale, ${ }^{118} \mathrm{~F}-$ FDG PET/CT in sarcoidosis management: review and report of 20 cases," European Journal of Nuclear Medicine and Molecular Imaging, vol. 35, no. 8, pp. 1537-1543, 2008.

[14] N. Milman, J. Mortensen, and C. Sloth, "Fluorodeoxyglucose PET scan in pulmonary sarcoidosis during treatment with inhaled and oral corticosteroids," Respiration, vol. 70, no. 4, pp. 408-413, 2003.

[15] R. G. Keijsers, F. J. Verzijlbergen, J. M. van den Bosch et al., "18FFDG PET as a predictor of pulmonary function in sarcoidosis," Sarcoidosis Vasculitis and Diffuse Lung Diseases, vol. 28, no. 2, pp. 123-129, 2011.

[16] F. Conti, G. Malviya, F. Ceccarelli et al., "Role of scintigraphy with ${ }^{99 m} \mathrm{Tc}$-infliximab predicting the response of intraarticular in patients with refractory monoarthritis," European Journal of Nuclear Medicine and Molecular Imaging, vol. 39, no. 8, pp. 13391347, 2012. 
[17] R. P. Baughman and M. Iannuzzi, "Tumour necrosis factor in sarcoidosis and its potential for targeted therapy," BioDrugs, vol. 17, no. 6, pp. 425-431, 2003.

[18] M. Steffen, J. Petersen, M. Oldigs et al., "Increased secretion of tumor necrosis factor-alpha, interleukin-1-beta, and interleukin- 6 by alveolar macrophages from patients with sarcoidosis," Journal of Allergy and Clinical Immunology, vol. 91, no. 4, pp. 939-949, 1993.

[19] M. W. Ziegenhagen, U. K. Benner, G. Zissel, P. Zabel, M. Schlaak, and J. Müller-Quernheim, "Sarcoidosis: TNF- $\alpha$ release from alveolar macrophages and serum level of sIL-2R are prognostic markers," The American Journal of Respiratory and Critical Care Medicine, vol. 156, no. 5, pp. 1586-1592, 1997.

[20] M. W. Ziegenhagen, M. E. Rothe, G. Zissel, and J. MüllerQuernheim, "Exaggerated TNF $\alpha$ release of alveolar macrophages in corticosteroid resistant sarcoidosis," Sarcoidosis Vasculitis and Diffuse Lung Diseases, vol. 19, no. 3, pp. 185-190, 2002.

[21] R. P. Baughman, S. A. Strohofer, J. Buchsbaum, and E. E. Lower, "Release of tumor necrosis factor by alveolar macrophages of patients with sarcoidosis," Journal of Laboratory and Clinical Medicine, vol. 115, no. 1, pp. 36-42, 1990.

[22] R. P. Baughman and E. E. Lower, "Infliximab for refractory sarcoidosis," Sarcoidosis Vasculitis and Diffuse Lung Diseases, vol. 18, no. 1, pp. 70-74, 2001.

[23] L. Mallbris, A. Ljungberg, M. A. Hedblad, P. Larsson, and M. Ståhle-Bäckdahl, "Progressive cutaneous sarcoidosis responding to anti-tumor necrosis factor- $\alpha$ therapy," Journal of the American Academy of Dermatology, vol. 48, no. 2, pp. 290-293, 2003.

[24] S. D. Roberts, D. S. Wilkes, R. A. Burgett, and K. S. Knox, "Refractory sarcoidosis responding to infliximab," Chest, vol. 124, no. 5, pp. 2028-2031, 2003.

[25] R. P. Baughman, M. Drent, M. Kavuru et al., "Infliximab therapy in patients with chronic sarcoidosis and pulmonary involvement," The American Journal of Respiratory and Critical Care Medicine, vol. 174, no. 7, pp. 795-802, 2006.

[26] E. Panselinas, J. K. Rodgers, and M. A. Judson, "Clinical outcomes in sarcoidosis after cessation of infliximab treatment," Respirology, vol. 14, no. 4, pp. 522-528, 2009.

[27] G. Malviya, F. Galli, I. Sonni, M. Pacilio, and A. Signore, "Targeting $\mathrm{T}$ and $\mathrm{B}$ lymphocytes with radiolabeled antibodies for diagnostic and therapeutic applications," Quarterly Journal of Nuclear Medicine and Molecular Imaging, vol. 54, no. 6, pp. 654-676, 2010.

[28] A. Signore, C. Lauri, and F. Galli, "Radiolabelled probes targeting infection and inflammation for personalized medicine," Current Pharmaceutical Design, vol. 20, no. 14, pp. 2338-2345, 2014.

[29] F. Conti, R. Priori, M. S. Chimenti et al., "Successful treatment with intraarticular infliximab for resistant knee monarthritis in a patient with spondylarthropathy: a role for scintigraphy with 99mTc-infliximab," Arthritis and Rheumatism, vol. 52, no. 4, pp. 1224-1226, 2005.

[30] M. Chianelli, C. D’Alessandria, F. Conti et al., "New radiopharmaceuticals for imaging rheumatoid arthritis," Quarterly Journal of Nuclear Medicine and Molecular Imaging, vol. 50, no. 3, pp. 217-225, 2006.

[31] C. D’Alessandria, G. Malviya, A. Viscido et al., "Use of a 99mTc labeled anti-TNF $\alpha$ monoclonal antibody in Crohn's disease: in vitro and in vivo studies," Quarterly Journal of Nuclear Medicine and Molecular Imaging, vol. 51, no. 4, pp. 334-342, 2007.
[32] A. Alavi, C. A. Buchpiguel, and A. Loessner, "Is there a role for FDG PET imaging in the management of patients with sarcoidosis?" Journal of Nuclear Medicine, vol. 35, no. 10, pp. 1650-1652, 1994.

[33] H. Zhuang and A. Alavi, "18-Fluorodeoxyglucose positron emission tomographic imaging in the detection and monitoring of infection and inflammation," Seminars in Nuclear Medicine, vol. 32, no. 1, pp. 47-59, 2002.

[34] G. El-Haddad, H. Zhuang, N. Gupta, and A. Alavi, "Evolving role of positron emission tomography in the management of patients with inflammatory and other benign disorders," Seminars in Nuclear Medicine, vol. 34, no. 4, pp. 313-329, 2004.

[35] L. H. Brudin, S. O. Valind, C. G. Rhodes et al., "Fluorine18 deoxyglucose uptake in sarcoidosis measured with positron emission tomography," European Journal of Nuclear Medicine, vol. 21, no. 4, pp. 297-305, 1994.

[36] Y. Nishiyama, Y. Yamamoto, K. Fukunaga et al., "Comparative evaluation of ${ }^{18}$ F-FDG PET and ${ }^{67} \mathrm{Ga}$ scintigraphy in patients with sarcoidosis," Journal of Nuclear Medicine, vol. 47, no. 10, pp. 1571-1576, 2006.

[37] E. Prager, M. Wehrschuetz, B. Bisail et al., "Comparison of 18FFDG and 67Ga-citrate in sarcoidosis imaging," NuklearMedizin, vol. 47, no. 1, pp. 18-23, 2008.

[38] A. S. Teirstein, J. Machac, O. Almeida, P. Lu, M. L. Padilla, and M. C. Iannuzzi, "Results of 188 whole-body fluorodeoxyglucose positron emission tomography scans in 137 patients with sarcoidosis," Chest, vol. 132, no. 6, pp. 1949-1953, 2007. 


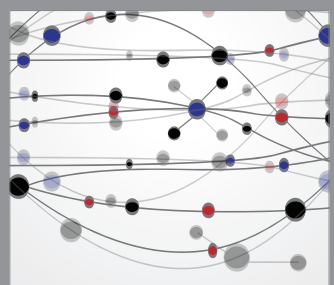

The Scientific World Journal
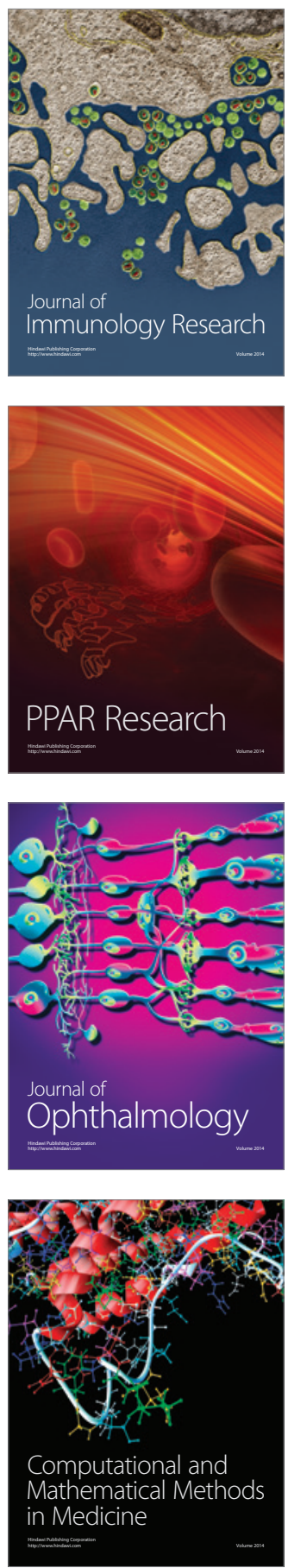

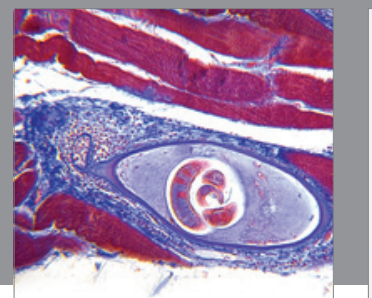

Gastroenterology

Research and Practice
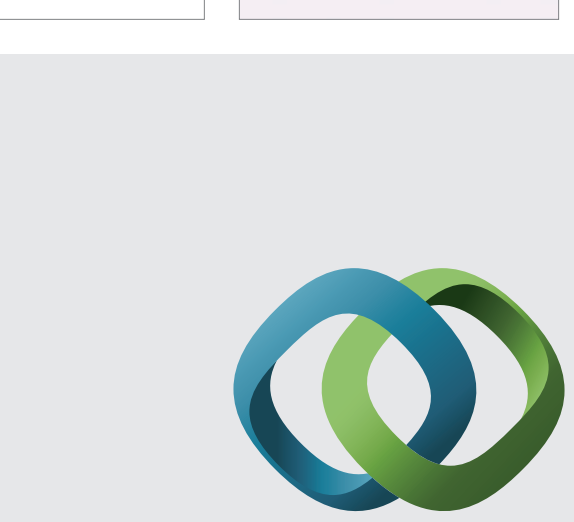

\section{Hindawi}

Submit your manuscripts at

http://www.hindawi.com
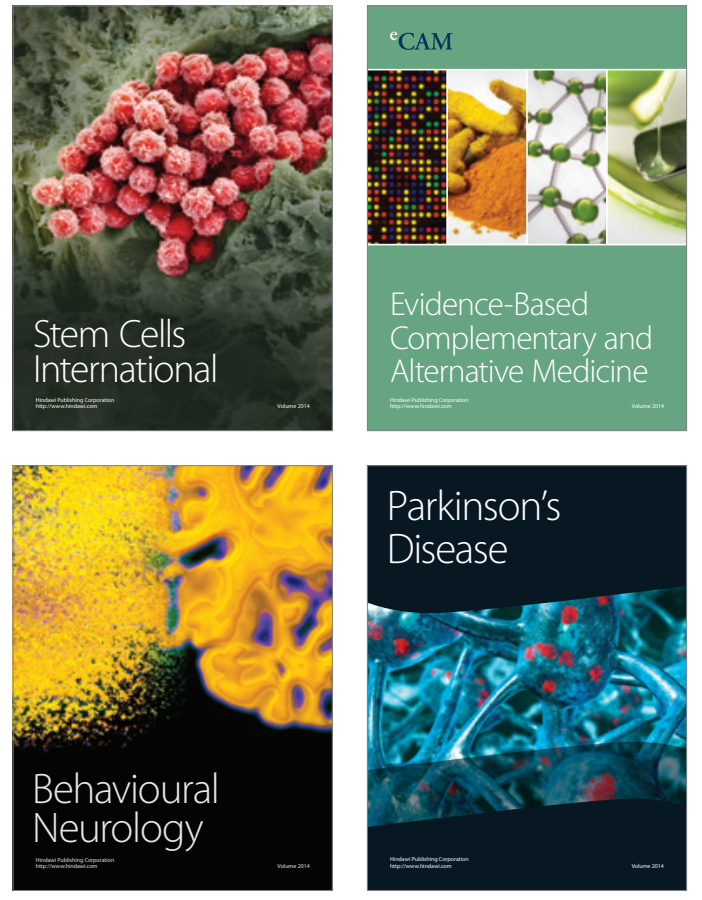
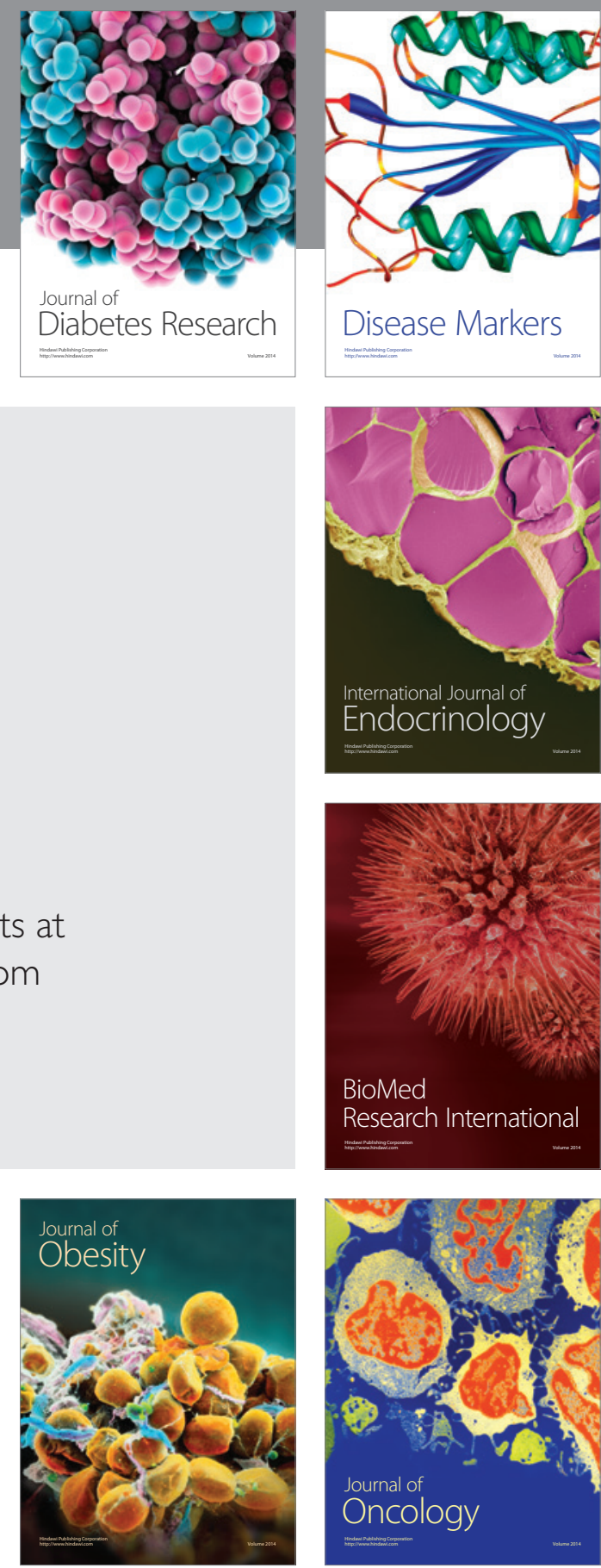

Disease Markers
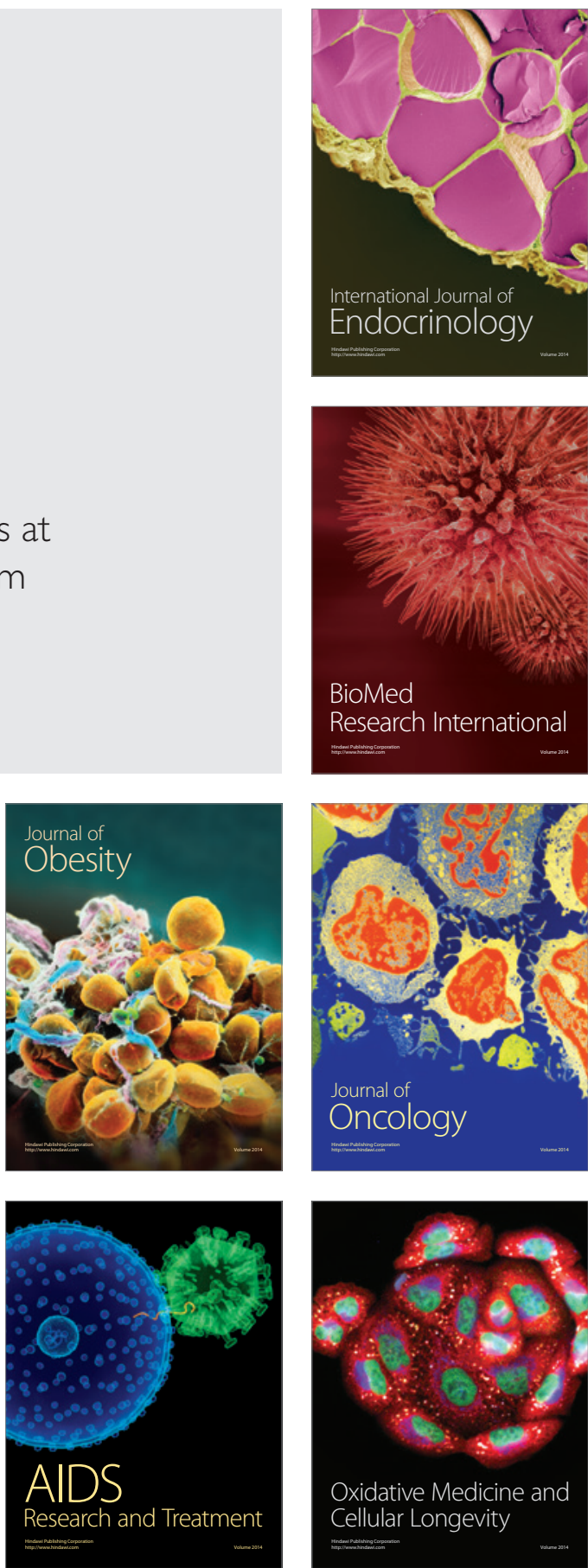